\title{
Bacteriemia por Eikenella corrodens secundaria a infección periodontal en paciente neutropénico
}

\section{Bacteraemia due to Eikenella corrodens secondary to periodontal infection in a neutropenic patient}

\author{
S. Junquera' ${ }^{1,2}$, H. Sáez de la Fuente ${ }^{2}$, M.A. Sáiz ${ }^{2}$, J. Lafita ${ }^{1}$
}

\section{RESUMEN}

Se expone el caso de un paciente de 44 años, sin antecedentes de interés, que presentó una infección sistémica por Eikenella corrodens posterior a una extracción dentaria en el contexto de una agranulocitosis de origen farmacológico por carbimazol. Durante el ingreso fue tratado con antibióticos de amplio espectro y G-CSF $5 \mu \mathrm{g} / \mathrm{kg} / \mathrm{día}$ con una evolución favorable y alta hospitalaria en el séptimo día.

Las infecciones invasivas por Eikenella corrodens, que desarrollan bacteriemia son menos del $20 \%$, generalmente son secundarias a drenaje de abscesos previos y suele aislarse junto a otros microorganismos, siendo excepcional el hallazgo de una bacteriemia primaria monomicrobiana sin la existencia previa de endocarditis. Es el primer caso de infección sistémica por esta bacteria secundaria a manipulación dental, en el que fue determinante el estado de inmunosupresión transitorio en el que se encontraba el paciente en ese momento para causar la infección diseminada.

Palabras clave. Eikenella corrodens. Bacteriemia. Agranulocitosis. Carbimazol.

\begin{abstract}
We present the case of a 44year-old patient, without significant previous medical history, who presented a systemic infection due to Eikenella corrodens following a dental extraction in the context of an agranulocitosis of pharmacological origin due to carbimazole. During admission he was treated with broad-spectrum antibiotics and G-CSF $5 \mu \mathrm{g} / \mathrm{kg} / \mathrm{day}$, undergoing a favorable evolution and receiving hospital discharge on the seventh day.

Invasive infections due to Eikenella corrodens that develop bacteriaemia are less than $20 \%$, and are generally secondary to the drainage of previous abscesses and are usually isolated together with other microorganisms; while finding a monomicrobial primary bacteriaemia without the prior existence of endocarditis is exceptional. This is the first case of systemic infection due to this bacteria secondary to dental manipulation, where the state of transitory immunosuppression in which the patient found himself at that time was determinant in causing the disseminated infection.
\end{abstract}

Key words. Eikenella corrodens. Bacteriaemia. Agranulocitosis. Carbimazole.
1. Servicio de Endocrinología. Complejo Hospitalario de Navarra.

2. Servicio de Microbiología. Hospital Santos Reyes. Aranda de Duero

\section{Correspondencia:}

Sonia Junquera Bañares

E-mail: sojuba@hotmail.com

Recepción: 28 de agosto de 2011

Aceptación provisional: 5 de octubre de 2011

Aceptación definitiva: 9 de noviembre de 2011 


\section{INTRODUCCIÓN}

Eikenella corrodens es un bacilo gramnegativo de carácter oportunista que forma parte de la microflora endógena de la boca, vías respiratorias superiores, tracto gastrointestinal y genitourinario. Se aísla en infecciones de cabeza y cuello, aparato respiratorio, heridas por mordedura humana y en abscesos de diferentes localizaciones. La infección que produce se caracteriza por ser de evolución lenta, generalmente polimicrobiana y suele acompañarse de una supuración fétida, simulando un proceso anaerobio. Sin embargo, es infrecuente que las infecciones invasivas causadas por esta bacteria desencadenen bacteriemia ${ }^{1}$.

\section{CASO CLÍNICO}

Varón de 44 años, natural de Mali, que acude al servicio de Urgencias por fiebre de seis horas de evolución y malestar general. Como antecedentes de interés cabe destacar enfermedad de Graves-Basedow en tratamiento con carbimazol $30 \mathrm{mg} /$ día desde hacía 6 semanas y la extracción del tercer molar inferior hacía cuatro días. En la exploración física se objetiva $\mathrm{T}^{\mathrm{a}} 39,5^{\circ} \mathrm{C}$, TA 122/71 y FC 137 l/min. Se palpa bocio grado 1a. En la boca se observan caries en varias piezas dentarias y enrojecimiento en la zona de extracción dentaria, siendo el resto de la exploración anodina. En el análisis de sangre se observan 500 leucocitos $/ \mathrm{mm}^{3}$ ( $0 \%$ neutrófilos) con el resto de series normal, PCR $321 \mathrm{mg} / \mathrm{dL}$, función tiroidea normalizada y sin otros datos de interés. Se toman muestra de orina, esputo y sangre para estudio microbiológico y se comienza con tratamiento antibiótico de amplio espectro (amikacina $20 \mathrm{mg} / \mathrm{Kg} /$ día y cefepime $2 \mathrm{~g} / 8$ horas). En el estudio de médula ósea que se hizo al día siguiente se detectó hipercelularidad con parada madurativa en serie mieloide, sin otros datos de interés, de probable etiología farmacológica, motivo por el que se suspendió el carbimazol y se comenzó tratamiento con G-CSF $5 \mu / \mathrm{kg} / \mathrm{d}$. Los tres días primeros del ingreso, el paciente tuvo dos episodios de fiebre de $39^{\circ} \mathrm{C}$, por lo que al cuarto día se cambió el tratamiento antibiótico previo por meropenem $1 \mathrm{~g} / 8$ horas y se añadió fluconazol $400 \mathrm{mg} /$ día, al tiempo que se realizó ecocardiograma transesofágico que descartó la presencias de endocarditis. Al quinto día desapareció la fiebre, coincidiendo con la recuperación parcial de la cifra de neutrófilos a $1.800 / \mathrm{mm}^{3}$, y al séptimo día se dio de alta por evolución favorable y resolución del cuadro.
A las 18 horas de incubación se detectó en los hemocultivos aerobio y anaerobio el crecimiento de un bacilo gramnegativo que se subcultiva posteriormente en diferentes medios sólidos en aerobiosis, anaerobiosis y en atmósfera enriquecida en $\mathrm{CO}_{2}$. A las 48 horas crecieron en Agar Columbia, Agar Chocolate y en Agar Brucella (no en medio McConkey) unas colonias de color amarillo pálidas, incrustadas en el agar y con olor a hipoclorito. Estas colonias fueron oxidasa positivas, catalasa negativas, ureasa e indol negativas, redujeron los nitratos a nitritos y no fermentaron los hidratos de carbono. En el estudio de sensibilidad que se realizó paralelamente por el método de Kirby-Bauer con placas de MuellerHinton sangre y con E-Test ${ }^{\circledR}$ AB BIODISK, la cepa aislada resultó sensible a todos los antibióticos testados (ampicilina, amoxicilina-ácido clavulánico, azitromicina, levofloxacino, ciprofloxacino, cefotaxima, cefuroxima, imipenen, cotrimoxazol y tetraciclinas), salvo a gentamicina y amikacina, con CMI de 16 y $32 \mu \mathrm{g} / \mathrm{mL}$, respectivamente. Su identidad fue confirmada por secuenciación del gen $16 \mathrm{~s}$.

\section{DISCUSIÓN}

Eikenella corrodens es un bacilo gramnegativo, anaerobio facultativo, que puede adoptar un aspecto pleomorfo o cocobacilar; inmóvil, no forma esporas, no tiene cápsula y su crecimiento se ve favorecido en medios con hemina e incubación en $\mathrm{CO}_{2}$ al $5-10 \%$. Crece en forma de colonias puntiformes, pequeñas y grisáceas (las más antiguas pueden adoptar un color amarillo pálido) y huelen a lejía. En ocasiones, pueden mostrar una discoloración ligeramente verdosa en agar sangre y hasta en un $50 \%$ de los casos producen depresiones muy características en el agar. Son oxidasa positivas, catalasa negativa salvo excepciones que son débilmente positivas, lisina descarboxilasa y ornitina descarboxilasa positivas, ureasa, gelatinasa, indol y esculina negativas, no fermentan los hidratos de carbono y reducen el nitrato a nitrito ${ }^{1}$.

Aunque se han descrito cepas productoras de betalactamasas mediadas por transposón, la mayor parte de las cepas son sensibles a ampicilina, ureidopenicilinas, cefalosporinas de segunda y tercera generación, carbapenemas, tetraciclinas y fluorquinolonas. Por el contrario, presentan sensibilidad variable frente a amino- 
glucósidos, tigeciclina, telitromicina y azitromicina; y son resistentes a cefazolina, metronidazol y clindamicina ${ }^{2}$.

Esta bacteria forma parte de la microflora endógena de la boca, vías respiratorias superiores, tracto gastrointestinal y genitourinario. Es de carácter oportunista y la infección que causa se caracteriza por ser de evolución lenta, con un intervalo que suele ser superior a una semana entre el momento de la lesión y la aparición de las manifestaciones clínicas de la enfermedad. La supuración que causa este tipo de infección suele ser fétida y simula un proceso anaerobio. Suele aislarse como un componente de infecciones mixtas, generalmente junto a estreptococos, y con frecuencia, en pacientes con algún grado de inmunodeficiencia ${ }^{3}$.

Entre los componentes de la superficie de $E$. corrodens que se pueden considerar como factores de virulencia, se encuentran los lipopolisacáridos, exopolisacáridos, proteínas de membrana externa, limo, adesinas y pilis. De hecho, parece que podrían estar relacionados los componentes de la superficie celular con el diferente grado de virulencia, que varía de unas cepas a otras ${ }^{1}$. Asimismo, se ha descrito la existencia de mayor diversidad clonal y mayor recambio de clones en el tiempo en los pacientes con infección periodontal que en los que tenían simple colonización por esta bacteria ${ }^{4}$.

La infección más frecuente en la que se ve involucrada es la de cabeza y cuello ${ }^{5}$, seguida de aparato respiratorio, infecciones intraabdominales, heridas por mordedura humana, infecciones ginecológicas asociadas a dispositivos intrauterinos y endocarditis en pacientes con valvulopatías y en pacientes adictos a drogas por vía parenteral. Es muy típico el aislamiento de esta bacteria en las infecciones por mordedura humana, sobre todo, en las lesiones de puño cerrado, y en infecciones de personas que se muerden los dedos o las uñas, y que por proximidad al hueso, pueden causar osteomielitis y/o artritis ${ }^{1}$.

Se han descrito dos casos de infección en dos pacientes jóvenes diabéticas debido a los microtraumas en la piel ocasiona- dos por la monitorización glucémica y la inyección de insulina. En una de ellas, las punciones rutinarias en un dedo produjeron un panadizo complicado con necrosis de la yema del dedo y del lecho de la uña, y la otra desarrolló un absceso agudo en el muslo, donde se inyectaba la insulina, que se resolvió después de drenaje y antibioterapia iv $^{6}$. Se han descrito abscesos cerebrales en pacientes con antecedentes de otitis media supurativa crónica ${ }^{7}$. Se ha aislado también en ulceración genital tras mordedura humana en pene ${ }^{8} \mathrm{y}$ en absceso vulvar de una paciente diabética tras prácticas de sexo oral'.

Hay autores que consideran que la infección por esta bacteria oportunista que forma parte de la microflora habitual de la boca, es el resultado de la transmisión de la misma desde la cavidad oral humana al resto de localizaciones, salvo una excepción donde consideran probable que la infección se adquiriera al realizar biopsia de la mucosa mediante una colonoscopia que se hizo al paciente pocos días antes de aparecer la infección ${ }^{10}$. De la misma manera, se han descrito casos de abscesos abdominales en pacientes que han sufrido daño en la mucosa gastrointestinal por cirugía o perforación $^{11}$.

Sin embargo, tras la revisión de la literatura médica, son escasos los trabajos publicados en los que se documenta la presencia de bacteremia por E. corrodens. En una revisión realizada de 43 casos de infecciones invasivas por $E$. corrodens, se detectan 8 bacteriemias (5 polimicrobianas), de las cuales, 4 fueron secundarias al drenaje de abscesos abdominopélvicos, una por absceso cerebral, una tiroiditis supurada y dos casos de endocarditis. Por lo tanto, la proporción de casos descritos de infección invasiva que desarrollan bacteriemia no superan el $20 \%{ }^{12}$. También está descrito un caso de paciente sano con bacteriemia por un absceso peritonsilar que se complicó con diseminación intratorácica, y posteriormente, pericarditis, mediastinitis, neumonía y pleuritis ${ }^{13}$. Asimismo, en un paciente oncológico con abdomen agudo también se aisló en sangre $E$. corrodens junto a un estreptococo del grupo $\mathrm{C}^{14} \mathrm{y}$ en 
otros dos casos de sepsis neonatal se aisló en cultivo puro ${ }^{15}$. Hasta la fecha no hay publicado ningún caso de aislamiento de esta bacteria en sangre de pacientes con fiebre de origen desconocido.

En nuestro paciente el factor determinante de la bacteriemia fue la manipulación dental favorecida por la situación de inmunosupresión transitoria en la que se encontraba en ese momento el paciente debido a carbimazol.

Se ha descrito por métodos de biología molecular el hallazgo de E. corrodens y otras bacterias saprófitas de la boca en el torrente sanguíneo hasta en un 50\% de pacientes después de un episodio de manipulación dental ${ }^{16}$. Este hallazgo puede no tener ninguna transcendencia en pacientes sanos con un sistema inmune indemne; sin embargo, puede ser el origen de una grave infección en pacientes inmunodeprimidos como el que se presenta.

\section{BIBLIOGRAFÍA}

1. Jaramillo RD, Suárez P, Barraza B, Lara P, TeHERÁN L, EsCAMILLA JE. Eikenella corrodens: patogénesis y aspectos clínicos. Colomb Med 2006; 37: 228-241.

2. Cercenado E, Cercenado S, Bouza E. In vitro activies of Tigecycline (GAR-936) and 12 other antimicrobial agents against 90 Eikenella corrodens clinical isolates. Antimicrobial Agents and Chemotherapy 2003; 47: 26442645.

3. Gasser I, Moreno G, Ferrer A, Capdevila JA, ValME I. Eikenella corrodens: five year experience in a general hospital. Enferm Infecc Microbiol Clin 1999; 17: 394-397.

4. Fujise O, Chen W, Rich S, Chen C. Clonal diversity and stability of subgingival Eikenella corrodens. J Clin Microbiol 2004; 42: 2036-2042.

5. Udaka T, Hiraki N, Shiomori T, Miyamoto H, FuJiMURA T, INABA T et al. Eikenellla corrodens in head and neck infections. J Infect 2007; 54: 343-348.
6. NEWField RS, VARGas I, Huma Z. Eikenella corrodens. Case report in two adolescent females with IDDM. Diabetes Care 1996; 19: 10111013.

7. Pit S, Jamal F, Cheah FK. Microbiology of cerebral abscess: a four-year study in Malaysia. J Trop Med Hyg 1993; 96: 191-196.

8. Rosen T. Penile ulcer from traumatic orogenital contact. Dermatol Online J 2005; 11: 18.

9. Öztoprak N, Bayar Ü, Celebri G, Basaran M, CöMERT F. Eikenella corrodens, cause of a vulvar abscess in a diabetic adult. Infect Dis Obstet Gynecol 2007; 17: 63565.

10. Heiro M, Nikoskelainen J, Engblom E, Kotilainen P. Eikenella corrodens prosthetic valve endocarditis in a patient with ulcerative colitis. Scand J Infect Dis 2000; 32: 324-325.

11. Lorenzo-Garde L, Bolaños-Rivero M, TuréganoGarcía A, Martín-Sánchez AM. Abscesos intraperitoneales por Eikenella corrodens. Rev Esp Quimioter 2011; 24: 115-116.

12. Sheng WS, Hsueh PR, Hung CC, Teng LJ, Chen YC, LUH KT. Clinical features of patients with invasive Eikenella corrodens infections and microbiological characteristics of the causative isolates. Eur J Clin Microbiol Infect Dis 2001; 20: 231-236.

13. Zgheib A, el Allaf D, Demonty J, Rovive G. Intrathoracic infections with bacteraemia due to Eikenella corrodens as a complication of peritonsilar abscesses: report of a case and review of the literature. Acta Clin Belg 1992; 47: 124-128.

14. MÖKEMÜLlER KE, BRONZE MS. Immunoblastic lymphadenopathy presenting as an acute abdomen and mixed bacteremia with Eikenella corrodens and group C streptococci. Am J Gastroenterol 1998; 93: 652-653.

15. Cendejas-Bueno E, Romero-Gómez MP, Sáez-Nieto JA, Omeñaca-Terés F, Ares-Segura S, PeÑa-García P. Sepsis neonatal por Eikenella corrodens. An Pediatr (Barc) 2007; 67: 603-614.

16. Castillo DM, Sánchez-Beltrán MC, Castellanos JE, SAnz I, MaYorga-FAYAd I, SAnz M et al. Detection of specific periodontal microorganisms from bacteraemia samples after periodontal therapy using molecular-based diagnostics. J Clin Periodontol 2011; 38: 418-427. 